\title{
Seasonal Variation of Essential Oil Yield and Composition of Sage (Salvia officinalis L.) Grown in Castilla - La Mancha (Central Spain)
}

\author{
María P. ARRAIZA, Carlos ARRABAL, José V. LÓPEZ \\ ETSI Montes. Universidad Politécnica de Madrid. Ciudad Universitaria S/N. 28040 Madrid, Spain; paz.arraiza@upm.es
}

\begin{abstract}
Links between phenology, yield and composition of the essential oil of common sage, Salvia officinalis L., grown in Guadalajara (Central Spain) were determined in the different phases of the biological cycle during one year. Data showed an average yield about $1.0 \%$. The analysis of the oil components was carried out by GC-FID and GC/MS. The main oil constituent was alpha thujone (40.1-46.5\%). Other identified compounds are beta pinene (2.6-4.5\%), cineole (3.5-8.7\%), beta thujone (4.1-5.6\%), camphor (4.1-8.0\%), borneol (1.3$3.7 \%)$, alpha humulene (3.8-7.3\%), viridiflorol (3.4-12.6\%) and manool (0.1-4.5\%). The highest yield of oil was obtained in the period of full flowering and the highest concentration of alpha thujone in the period of initial flowering.
\end{abstract}

Keywords: alpha thujone, essential oil composition, Salvia officinalis, Spain

\section{Introduction}

Aromatic and medicinal plants make up an interesting group because of the active principles they content. Cultivation of these species has a long tradition in Central Spain (Gaviña, 1966; Torner, 1974) and is an alternative to farming surpluses and to exploitation of abandoned lands, as well as a handful tool for diversification.

Sage is the general name for the herbs of the Salvia species, all of which are native of southern Europe and the Western Mediterranean. Common sage, Salvia officinalis $\mathrm{L}$., is a perennial herb of the Labiatae family and is now produced worldwide. Sage oil has a camphoraceous, thujone-like aroma and is used in the fragrance industry. The oil of Salvia officinalis is also known for its medicinalbiological activities, such as antimicrobial and fungicidal effects (Barlcevic et al., 2000; Carta et al., 1996; Edris et al., 2007).

ISO 9909 for medicinal uses regulates the amounts of several constituents in the sage essential oils: cis-thujone (18.0-43.0\%), camphor (4.5-24.5\%), 1,8 cineole ((5.5-13.0\%), trans-thujone (3.0-8.5\%), alpha-humulene (>12.0\%), alpha-pinene (1.0-6.5\%), camphene (1.5-7.0\%), limonene (0.5-3.0\%), bornyl acetate $(>2.5 \%)$ and linalool + linalyl acetate $(>1 \%)$.

The oil is obtained by steam distillation from fresh or dried leaves and flowering tops of the plant. Oil yield is between 1.4 and $2.0 \%$. The composition of oil of $S$. officinalis from different countries has been studied by several authors (Fellah et al., 2006; Kanias et al., 1998; Pino et al., 1997; Radulescu et al., 2004; Tsankova et al., 1994; Velickovic et al., 2002). It is composed mainly of monoterpene and sesquiterpene hydrocarbons and their oxygen derivates. Seasonal variation of oil of $S$. officinalis has also been reported (Asllani, 2000; Mirjalili et al., 2006; Perry et al., 1999; Pitarevic et al., 1984; Santos-Gomez and Fernandez-Ferreira, 2001).

The aims of the present paper were (a) to study the variation of the yield of oil, (b) to characterize the chemical composition of the oil and (c) to assess the evolution of the volatile active principles present in sage oil during one year.

\section{Material and methods}

\section{Plant material}

Samples of $S$. officinalis were collected from the cultivations belonging to the Centro Agrícola of Marchamalo (dependent on the Delegation of Agriculture and Environment of Guadalajara), between November 2008 and August 2009. Collection took place once a month during all the phenological periods, except full flowering and after flowering, when two or three samples were taken. The upper $20 \mathrm{~cm}$ aerial parts were harvested manually and dried in a ventilated chamber to constant weight. Water content was determined by azeotropic distillation with xylene.

\section{Distillation}

The oil was obtained by hydrodistillation of the dried ground material (only leaves or leaves and flowers, depending on each phenological period, because farmers do not distill leaves and flowers separately). The distillation was carried out in a Clevenger-type apparatus, according to the French Pharmacopeaea (IX Ed.). The oil was recovered directly and was stored with anhydrous $\mathrm{Na}_{2} \mathrm{SO}_{4}$ in dark vials at $4^{\circ} \mathrm{C}$. 
Gas Chromatography/Mass Spectrometry

GC/MS Samples were analysed by means of gas chromatography/mass spectrometry using an HP 5890A gas chromatograph connected to an HP 5971 A mass detector $(\mathrm{EI}, 70 \mathrm{eV})$ and equipped with a $30 \mathrm{~m} \times 0.25 \mathrm{~mm}$ internal diameter, DB-5 column ( $0.25 \mathrm{~mm}$ film thickness), upon the following conditions: injector temperature $260^{\circ} \mathrm{C}$, column temperature $60^{\circ} \mathrm{C}(2 \mathrm{~min}), 4^{\circ} \mathrm{C}(1 \mathrm{~min}), 260^{\circ} \mathrm{C}(5$ $\mathrm{min})$, carrier gas $\mathrm{He} 1 \mathrm{~mL} / \mathrm{min}$, split 1:20, scan time $1 \mathrm{~s}$., acquisition mass range $40-650 \mathrm{~m} / \mathrm{z}$.

The composition of the oil of $S$. officinalis was determined by comparing the relative GC retention times and the mass spectra of oil components with those of authentic compounds and the mass spectral data obtained from libraries.

\section{Gas Chromatography/Flame Ionization Detection ( $G C$ ) FID)}

A gas chromatograph Hewlett Packard HP 5890 Series II, equipped with flame ionization detector (FID), an auto sampler and a split-splitless injector was used. The capillary column and conditions were similar to GC/MS. The temperature of FID was $270^{\circ} \mathrm{C}$. The quantitative data were expressed as relative percentage of the oil constituents calculated from the GC peak areas without using correction factors. Each determination was carried out in duplicate.

\section{Chemicals}

Alpha thujone, beta pinene, cineole, beta thujone, camphor, borneol and alpha humulene were obtained from Sigma-Aldrich. All compounds were analytical standard grade and anhydrous $\mathrm{Na}_{2} \mathrm{SO}_{4}$ was analytical reagent grade from Panreac.

\section{Results and discussion}

Tab. 1 shows the yield of oil obtained from every sample for each phenological period.

Tab. 1. Essential oil yield (\% v/w) of Salvia officinalis

\begin{tabular}{cc}
\hline Sample & Yield $(\% \mathrm{v} / \mathrm{w})$ \\
\hline VS1 & 0.6 \\
\hline VS2 & 0.7 \\
VS3 & 0.8 \\
\hline VS4 & 0.8 \\
\hline IF1 & 0.7 \\
\hline IF2 & 1.1 \\
\hline IF3 & 1.2 \\
\hline FF1 & 1.4 \\
\hline FF2 & 1.5 \\
FF3 & 1.3 \\
AF1 & 1.0 \\
AF2 & 1.0 \\
AF3 & 0.9 \\
AF4 & 0.8 \\
\hline
\end{tabular}

$\overline{\mathrm{VS}}=$ Vegetative Stage; IF = Initial Flowering; FF = Full Flowering; AF = After Flowering
The oil yield was calculated referring volume of oil to weight of every dried sample. Data and calculations are referred to leaves, and also flowers during flowering periods. The average oil yield $(\mathrm{v} / \mathrm{w})$ was approximately $1.0 \%$. It is higher during initial and full flowering (1.1-1.5 \%), being lower after flowering and in the vegetative stand period (less than $1.0 \%$ ).

Tab. 2 shows the qualitative and average quantitative composition of the main constituents in the oil samples of sage obtained during the period of full flowering.

Tab. 2. Average composition of Salvia officinalis during the vegetative cycle

\begin{tabular}{|c|c|c|c|}
\hline Compound & $\begin{array}{c}\text { Percentage } \\
(\%)\end{array}$ & Compound & $\begin{array}{c}\text { Percentage } \\
(\%)\end{array}$ \\
\hline \multicolumn{2}{|c|}{ Monoterpenes } & borneol & 2.5 \\
\hline alpha-pinene & 4.7 & bornyl acetate & 0.3 \\
\hline camphene & 0.8 & \multicolumn{2}{|c|}{ Sesquiterpenes } \\
\hline beta-pinene & 1.9 & caryophyllene & 1.8 \\
\hline myrcene & 1.2 & alpha-humulene & 4.6 \\
\hline p-cymene & 1.0 & gamma cadinene & 0.5 \\
\hline 1,8 cineole & 6.7 & viridiflorol & 8.1 \\
\hline alpha-thujone & 43.6 & \multicolumn{2}{|c|}{ Diterpenes } \\
\hline beta-thujone & 5.1 & manool & 1.7 \\
\hline camphor & 8.1 & & \\
\hline
\end{tabular}

Qualitative composition is similar to that described in literature (Perry et al., 1999; Pino et al., 1997; SantosGomes and Fernandes-Ferreira, 2001), not so the quantitative content. The constituents alpha-pinene, beta-pinene, 1,8 cineole, alpha-thujone, beta-thujone, camphor, borneol, alpha-humulene, viridiflorol, and manool account at least $81 \%$ of weight in all samples. This quantitative composition of the samples is quite related to samples reported in Arouca, Portugal (Santos-Gomes and Fernandes-Ferreira, 2001) and New Zealand (Santos-Gomes and FernandesFerreira, 2001) and meets the requirements of ISO 9909 (1999) standard for all compounds except camphene.

Tab. 3 presents the average values (\%) found for the main constituents in each phenological period.

Tab. 3. Content (\%) of each major constituent in all phenological phases

\begin{tabular}{ccccc}
\hline & VS & IF & FF & AF \\
\hline alpha-pinene & 4.8 & 4.8 & 4.7 & 4.3 \\
\hline beta-pinene & 2.6 & 1.3 & 1.2 & 2.4 \\
\hline 1,8 cineole & 8.7 & 4.7 & 3.5 & 9.8 \\
alpha-thujone & 40.1 & 48.3 & 46.5 & 39.5 \\
\hline beta-thujone & 4.1 & 5.8 & 5.6 & 4.7 \\
\hline camphor & 4.1 & 8.3 & 8.0 & 12.1 \\
\hline borneol & 1.3 & 3.8 & 3.7 & 1.0 \\
\hline alpha-humulene & 7.3 & 4.0 & 3.8 & 3.3 \\
viridiflorol & 12.2 & 12.6 & 4.3 & 3.4 \\
\hline manool & 1.2 & 4.5 & 0.1 & 1.1 \\
\hline
\end{tabular}

VS = Vegetative Stage; IF = Initial Flowering; FF = Full Flowering; AF = After Flowering 
108

The results show a chemotype with a proportion of alpha and beta thujone of 10:1, having high (44 - 54\%) total thujone (alpha and beta) content, according to Perry et al. (1999).

The percentage of each major constituent in the oil was found to vary during all the phenological periods. It was observed that alpha-pinene, alpha-thujone, beta-thujone, borneol, viridiflorol and manool have a higher percentage during initial flowering, while cineole and camphor show a higher value after full flowering. Alpha-humulene reaches its higher percentage during the vegetative stand period.

The variation of alpha-thujone is different to that described by Asllani (2000) and Santos-Gomes and Fernandes-Ferreira (2001), where the maximum value is reported during the vegetative stand.

In conclusion, the best moment for harvesting is the initial flowering period, if the objective is a high content in alpha-thujone, and during full flowering, if the objective is a high yield in essential oil.

\section{References}

Asllani U (2000). Chemical composition of Albanian sage oil (Salvia fficinalis L.). J Essential Oil Res 12:79-84.

Barlcevic D, Bartol T (2000).SAGE-The Genus Salvia. (Kintzios SE Ed.). Harwood Academic Publishers, Amsterdam, 143 $184 \mathrm{p}$.

Carta C, Moretti M, Peana A (1996). Activity of the oil of Salvia officinalis L. against Botrytis cinerea. J Essential Oil Res 6:173-179.

Edris AE, Jirovetz L, Buchbauer G, Denkova Z, Stoyanova A, Slavchev A (2007). Chemical Composition, Antimicrobial Activities and Olfactoric Evaluation of a Salvia officinalis L. (Sage) Essential Oil from Egypt. Essent Oil Res 19(2):186189.

Fellah S, Diouf PN, Petrissans M, Perrin D, Romdhane M, Abderrabba M (2006).Chemical composition and antioxidant properties of Salvia officinalis L. oil from two culture sites in Tunisia. J Essential Oil Res 18(5):553-556.
Gaviña M (1966). Contribución al estudio de los aceites esenciales españoles I (Cuenca) y II (Guadalajara). INIA, Spain.

Kanias GD, Souleles C, Loukis A, Philotheou-Panou E (1998). Statistical study of essential oil composition in three cultivated sage species. J Essential Oil Res 10(4):395-403.

Mirjalili MH, Salehi P, Sonboli A, Vala MM (2006). Essential oil variation of Salvia officinalis aerial parts during its phenological cycle. Chem Nat Comp 42(1):19-23.

Perry NB, Anderson RE, Brennan NJ, Douglas MH, Heaney AJ, McGimpsey JA, Smallfield BM (1999). Essential oils from Dalmatian sage (Salvia officinalis L.): variations among individuals, plant parts, seasons, and sites. J Agric Food Chem 47(5):2048-2054.

Pino JA, Estarrón M, Fuentes V (1997). Essential oil of sage (Salvia officinalis L.) grown in Cuba. J Essential Oil Res 9(2):221-222

Pitarevic I, Kuftinec J, Blazevic N, Kustrak D (1984). Seasonal variation of essential oil yield and composition of dalmatian sage, Salvia officinalis. J Natural Prod 409 p.

Radulescu V, Chiliment S, Oprea E (2004). Capillary gas chromatography-mass spectrometry of volatile and semivolatile compounds of Salvia officinalis. J Chromatogr A 1027:121-126.

Santos-Gomes PC, Fernandes-Ferreira M (2001). Organ- and season-dependent variation in the essential oil composition of Salvia officinalis L. cultivated at two different sites. J Agric Food Chem 49:2908-2916.

Torner J (1974). Contribución al estudio de los aceites esenciales españoles II (Guadalajara). INIA, Spain.

Tsankova ET, Konaktchiev AN, Genova EM (1994). Constituents of essential oils from three Salvia species. J Essential Oil Res 6:375-378.

Velickovic D, Ristic M, Randjelovlc N, Smelcerovic A (2002). Chemical composition and antimicrobial characteristics of the essential oils obtained from flower, leaf and stem of Salvia officinalis L. originated from southern Serbia. J Essential Oil Res 14:453-458. 